\title{
Kamil Zeidler
}

\section{Estetyka prawa - ujęcie zewnętrzne i wewnętrzne}

\section{Wprowadzenie}

Pomysł zajęcia się problematyką estetyki prawa może w pierwszym momencie budzić zdziwienie, a nawet prowadzić do wniosku, że jest ona kolejnym pobocznym i nieistotnym - z punktu widzenia głównych nurtów dociekań filozofii, a zwłaszcza teorii prawa - pomysłem, który prawdopodobnie nie jest godny szerszej uwagi. Niewątpliwie, problematyka estetyki prawa nie pojawia się w polskiej literaturze teoretyczno- i filozoficznoprawnej wprost, a przynajmniej te problemy, które są ze stanowiska estetycznego doniosłe, nie zawsze są w tej perspektywie postrzegane, a tym bardziej szczegółowo badane, choć można wskazać kilka doniosłych przykładów tego typu refleksji właśnie w pracach polskich badaczy. Warto jednak już teraz podkreślić, że w literaturze zagranicznej, zwłaszcza anglojęzycznej, rozważania z zakresu estetyki prawa są obszerne, ciekawe i inspirujące, a samo pojęcie estetyki prawa jest już tam ugruntowane ${ }^{1}$.

Celem niniejszego opracowania będzie wykazanie, że obszerna problematyka, która obejmuje estetyczną refleksję nad prawem, jest nie tylko polem ciekawym, lecz - co więcej - może okazać się polem ważnym także w wymiarze praktycznym. Poniższe rozważania należy jednak traktować jako swego rodzaju „spis treści”, dookreślający problematykę estetyki prawa, jak również stanowiący swoistą „mapę”, na której wiele już widzimy, ale nadal możemy znaleźć terra incognita.

1 Zob.: R. Kevelson (ed.), Law and Aesthetics, „New Studies in Aestetics”, vol. 11, New York 1992; C. Douzinas, L. Nead (eds), Law and the Image: The Authority of Art and the Aesthetics of Law, Chicago 1999; D. Manderson, Songs without Music: Aesthetic Dimensions of Law and Justice, Berkeley 2000; A. Gearey, Law and Aesthetics, „Legal Theory Today” 2003, vol. 13, no. 2; E. M. Morgan, The Aesthetics of International Law, Toronto 2007; O Ben-Dor (ed.), Law and Art: Justice, Ethics and Aesthetics, Routledge 2011; L. Dahlberg (ed.), Visualising Law and Authority: Essays on Legal Aesthetics, Belin-Boston 2012; zob. też: J. J. Costonis, Law and aesthetics: A critique and a reformulation of the dilemmas, „Michigan Law Review” 1982, vol. 80, no. 3, s. 355-461; M. F. Carneiro, Direito, estética e arte de julgar, Porto Alegre 2008, s. 67-95. 


\section{Ujęcie wewnętrzne i zewnętrzne}

Podczas badania jakiegoś systemu, w tym systemu normatywnego, na proces badawczy rzutuje także to, w jakim stosunku pozostaje badacz do przedmiotu badanego. Może on badać system, w stosunku do którego jest na zewnątrz w tym sensie, iż nie jest elementem badanego systemu lub nie uznaje jego zasad, albo też są mu one obojętne. Przedmiotem badania może być również system, do którego badacz niejako należy, jest on jego elementem, w jakimś stopniu jest mu podporządkowany - czy to w sensie formalnym, czy w sensie faktycznym, czy w obu. Oba wskazane wyżej podejścia mają swe wady i zalety. Pierwsze pozwala - co do zasady - na większy obiektywizm, ale najczęściej naznaczone jest brakiem empirycznej refleksji na temat przedmiotu badania, bowiem badacz znajduje się poza systemem. Drugie - przeciwnie - daje możliwość poznania przedmiotu badanego niejako od środka, ale może to rzutować na zajęcie pozycji nawet skrajnie subiektywnej wobec przedmiotu badanego.

Najlepszą więc sytuacją jest wzajemne uzupełnianie się tych dwóch stanowisk badawczych. Przywołane dwa punkty widzenia w pewnym zakresie uzupełniają się bowiem w tworzeniu pełnego obrazu przedmiotu badanego. Grzegorz L. Seidler tak pisze o spojrzeniu zewnętrznym:

Fakty mówią tylko o jednej stronie zjawiska, możemy je opisywać i ustalać z większą lub mniejszą dokładnością, możemy je analizować i wyciągać z nich hipotetyczne wnioski, ale nie mówią one nam wiele o nastrojach i emocjach związanych z tymi faktami. Możemy, na przykład, posiadać wiele danych dotyczących Akademii Platońskiej, ale trudno nam będzie w oparciu o nie odtworzyć panującą tam atmosferę².

A właśnie w przypadku rozważań z zakresu estetyki, zwłaszcza przyjmując pozycję subiektywizmu poznawczego, owe „nastroje i emocje” dotyczące kontaktu z przedmiotem wartościowanym mają istotne znaczenie. Stąd estetyka prawa, w zakresach niżej przedstawionych, może być przedmiotem zarówno oglądu zewnętrznego, jak i wewnętrznego. W konkretnych rozważaniach zaś pojawiać się będzie dopiero możliwość wskazania, który ogląd jest w danej sytuacji bardziej celowy i użyteczny.

\section{Zarys przedmiotowy}

Może się wydawać, że estetyka prawa wpisuje się w postmodernistyczny nurt rozważań nad prawem, jak też nad zdarzeniami przeszłymi. Warto wspomnieć jednak, że już Gustaw Radbruch, inspirowany osobistymi zainteresowaniami artystycznymi, podejmował tematykę estetyki prawa, pisząc:

2 G. L. Seidler, W poszukiwaniu naczelnej idei, Lublin 2002, s. 80. 
Prawo może posługiwać się sztuką, a sztuka prawem. Podobnie jak wszystkie inne wytwory kultury prawo potrzebuje zmysłowego medium, które pozwala je wyartykułować: języka, gestu, togi, insygniów, symboliki, okazałej architektury. A zatem zmysłowe środki ekspresji prawa na równi z innymi tego rodzaju środkami podlegają ocenie estetycznej³.

Przed tym autorem wielu również zajmowało się tego rodzaju problematyką, ale wydaje się, że on pierwszy posługiwał się tym pojęciem wprost. Stąd zdecydowanie wzbraniam się od próby charakteryzowania estetyki prawa z tego tylko punktu widzenia, gdyż może to raczej dotyczyć metod i sposobów jej uprawiania - a to można czynić zarówno tradycyjnie, żeby nie powiedzieć konserwatywnie, jak i postmodernistycznie, podobnie jak uprawiana jest sama estetyka - jako dział filozofii - od początku XX w. aż po dziś dzieńn .

Starając się zarysować przedmiotowy zakres zainteresowań estetyki prawa, należy zacząć od wyróżnienia m.in.: 1) ogólnych problemów estetyki prawa, które obejmuja próby skonstruowania definicji estetyki prawa i wyjaśnienia jej podstawowych pojęć; 2) problemów dotyczących wartości estetycznej i wartościowania jako określonej aktywności intelektualnej; 3) porównywania działalności z zakresu estetyki do działalności prawniczej; 4) prawa i jego zjawiska jako przedmiotu estetyki, co dotyczy zarówno kształtu i formy prawa, jak i jego treści; 5) różnego rodzaju wytworów kultury, w tym dzieł literackich czy dzieł sztuk pięknych, które odnoszą się do prawa i jego zjawisk.

Zwłaszcza te dwa ostatnie punkty dostarczają najwięcej materiału badawczego, dotyczą one bowiem np. wątków prawniczych w literaturze pięknej czy procesu sądowego jako przedstawienia o charakterze dramatu (a niekiedy i komedii). $\mathrm{Z}$ drugiej strony zaś działalność stricte prawnicza może być postrzegana i badana jako działalność twórcza, czyli można ją, a także jej efekty, oceniać z punktu widzenia estetyki - jak zauważa chociażby Maria Szyszkowska: „Działalność legislacyjna to jedna z odmian twórczości"s.

\section{Law and literature}

Najbardziej chyba znanymi badaniami z zakresu estetyki prawa są badania określane mianem ,prawo i literatura” (law and literature), znane też pod nazwą „literackiej szkoły prawa"6. Jest to jednak tylko jeden wymiar estetyki

3 Zob. G. Radbruch, Filozofia prawa, Warszawa 2009, s. 116.

${ }_{4}$ Zob. szerzej: B. Dziemidok, Główne kontrowersje estetyki współczesnej, Warszawa 2002, passim.

5 M. Szyszkowska, Pomniki i prawo, „Gazeta Sądowa” 1996, nr 19-1997, nr 1.

6 Zob. M. Wierzbicki, Literacka szkoła prawa, [w:] J. Zajadło (red.), Leksykon współczesnej teorii i filozofii prawa. 100 podstawowych pojęć, Warszawa 2007, s. 177-179. Choć nazwa ta wydaje się o tyle niewłaściwa, że wskazuje, jakoby można było mówić o jakiejś konkretnej szkole prawa, a jest to raczej dość rozproszony nurt badawczy; zob. też: K. Zeidler, Prawo i literatura: Law 
prawa, zawężony przedmiotowo do rozważań bądź nad zawartością treści prawnych i prawniczych w dziełach literackich (tzw. nurt zewnętrzny), bądź nad wartością literacką aktów normatywnych, a szerzej także innych aktów stosowania prawa, które mogą przybrać postać pisemną, tak jak uzasadnienia do wyroków, a nawet prace prawnicze (tzw. nurt wewnętrzny). Okazuje się bowiem, że wiele dzieł literackich zawiera w sobie ogromny ładunek treści moralnych czy prawniczych, żeby wspomnieć choćby przykład Antygony, gdzie jakże wyraźnie rysuje się najdonioślejszy od wieków spór pomiędzy postawą prawnonaturalną a pozytywistyczną?

Przywołując inny przykład, Anna Teissier-Ensminger analizuje wartość estetyczną Kodeksu Napoleona z 1804 r. oraz silne oddziaływanie jego estetycznego bogactwa na francuską kulturę prawną, a także literacką. Rozważania autorki koncentrują się na tym akcie normatywnym jako dziele iście literackim, spełniającym określone wymogi formalne, jak również atrakcyjnym w samej treści ${ }^{8}$. Autorka w rozprawie opisuje cechy formalne tego kodeksu zarówno z prawnego, jak i literackiego punktu widzenia. Współdecydują one o uznaniu tego aktu za najwyższe osiągnięcie francuskiej sztuki prawodawczej, a jednocześnie także za artefakt estetyczny, któremu przysługuje atrybut piękna i który tym samym stanowi źródło przeżyć estetycznych - co spowodowało, iż Kodeks Napoleona doczekał się recepcji w literaturze, przede wszystkim poprzez umieszczanie wątków prawniczych w dziełach literackich. Autorka idzie jeszcze dalej, nazywając twórców kodeksu poetami, którzy sprowokowali narodziny literackiego nurtu interpretacji prawa. Kodeks jest zatem rozumianym dwojako - jako akt prawny i jako utwór literacki - i tym samym jest przedmiotem dwóch sposobów interpretacji, a każdy z nich posługuje się przy tym środkami właściwymi dla swojej dziedziny i dla wynikających z niej celów. Warto dodać, że w podobną stronę podążają rozważania dotyczące prawa w filmie?

\section{Retoryka}

W warstwie werbalnej od kierunku określanego mianem „prawa i literatury” pozostaje już tylko krok do estetycznych rozważań nad mową prawniczą, czyli sprowadzeniem tych badań do jednego z aspektów retoryki, który zawiera się w funkcji estetycznej wypowiedzi. Łatwo spostrzec, że przecież sama retoryka

and Literature, [w:] J. Zajadło, K. Zeidler (red.), Filozofia prawa w pytaniach i odpowiedziach, Warszawa 2013, s. 214-219.

7 Zob. C. Douzinas, R. Warrington, Justice Miscarried: Ethics and Aesthetics of Law, Hempstead 1994, passim.

8 Zob. A. Teissier-Ensminger, La fortune esthétique du Code civil des Français, Paris 2004.

9 Zob. L. Moran, E. Loizidou, I. Christie, E. Sandon (eds), Law's Moving Image, Routledge 2004; P. Grabarczyk, T. Stempowski (red.), Prawo w filmie, Warszawa 2009. 
posiada polityczno-prawny rodowód, a wymiar estetyczny mów politycznych i sądowych zawsze stanowił jej doniosły fragment. Tu jednak tę - jakże fascynującą i obszerną - płaszczyznę badawczą tylko sygnalizuję.

\section{Sala sądowa}

„Teatrem”, gdzie „dzieje się” prawo, jest od wieków sala sądowa. Jak wiemy, nie jest to miejsce zwykłe, a wręcz przeciwnie - miejsce niemal magiczne. Pisze o tym m.in. Jolanta Jabłońska-Bonca: „Konwencjonalne miejsca, formy, barwy, stroje, gesty pomagają zmitologizować władzę i prawo tak, aby ich autorytet wykroczył poza racjonalne ramy i oparł się na emocjach zbiorowości" ${ }^{10}$. I dodaje: „Proces sądowy stanowi w pewnym sensie spektakl ze swoją sceną, scenariuszem, aktorami, kostiumami, akcją. Prawnik, także u progu XXI wieku, powinien zdawać sobie z tego sprawę i umiejętnie korzystać z tego aspektu wzmacniającego jego pozycję"11. Autorka wskazuje tym samym na praktyczny wymiar owego „teatru”. Natomiast Maciej Zieliński zwraca uwagę, że: „dla ułatwienia orientacji w tym, iż jakiś podmiot posiada globalne kompetencje, wyposaża się go w pewne atrybuty zewnętrzne posiadania tych kompetencji, np. w mundur z odpowiednimi dystynkcjami, w togę i ozdobny łańcuch, w buławę""12.

Podobnie można tu wspomnieć o sali posiedzeń w parlamencie - tam także rozgrywa się swego rodzaju teatr polityczny, z rozpisanymi rolami, sformalizowanymi regułami, jawnymi i ukrytymi celami, a także dziełem, które tam powstaje, a którym jest prawo.

\section{Prawo w sztukach pięknych}

Przedmiotem estetyki prawa jest prawo i jego symbole w sztuce, ich przedstawienia w sztuce ${ }^{13}$. Stałymi motywami inspirującymi artystów na przestrzeni wieków były przede wszystkim: 1) sąd ostateczny ${ }^{14}$; 2) sąd ludzki; 3) przedstawienia Temidy; 4) zbrodnia, kara i jej wykonanie; 5) sami prawnicy. Motywy te pojawiały się w historii sztuki w różnym czasie i z różną intensywnością, ale niewątpliwie są dość stałe, choć zmienia się ich znaczenie i interpretacja. W najszerszym

${ }^{10}$ J. Jabłońska-Bonca, Prawnik a sztuka negocjacji i retoryki, Warszawa 2002, s. 85.

${ }^{11}$ Ibidem, s. 85.

${ }^{12}$ M. Zieliński, Wykładnia prawa. Zasady, reguły, wskazówki, Warszawa 2002, s. 28.

${ }^{13}$ L. Dahlberg (ed.), op. cit.

${ }^{14}$ Jak podkreśla Michał Walicki: „[...] przedstawienia Sądu Ostatecznego nie tylko i nie wyłącznie zawisały we wnętrzach kościołów; malowano je także z przeznaczeniem dla sali sądowej ratusza, gdzie umieszczone ponad krzesłem sędziego miały za zadanie uprzytamniać zebranym powagę procesu oraz istnienie norm etycznych najwyższego rzędu" - M. Walicki, Hans Memling. Sqd Ostateczny, oprac. J. Białostocki, Warszawa 1981, s. 16. 
ujęciu tak rozumianych badań z zakresu estetyki prawa poszukuje się wszystkich punktów łączących prawo i sztukę ${ }^{15}$. A prosty test pokazuje powszechność ich występowania w najróżniejszym kontekście, począwszy od sztuki wysokiej, poprzez kicz, aż po karykaturę czy żart ${ }^{16}$.

\section{Pictorial law}

Obrazy ujęte szerszej - w sensie tego, co możemy zmysłowo postrzegać, wykorzystując zmysł wzroku - także mogą stanowić przedmiot refleksji estetycznej. Prawdopodobnie najdalej w swych rozważaniach idzie Volker Boehme-Neßler w książce pt. Pictorial Law ${ }^{17}$. Zdaniem tego autora fakt, że żyjemy w wieku obrazu, który jest wszechobecny we współczesnym świecie, rzutuje również na prawo, jego odbiór, rozumienie i stosowanie. Boehme-Neßler nie koncentruje się jednak na dziełach sztuki, a raczej na technologicznych możliwościach przekazywania obrazu. Jego zdaniem siłą napędową tego kierunku rozwoju prawa - które podąża kilka kroków za rzeczywistością - jest współczesna technologia, a także - jak ją określa - technofilia; procesy te wyhamowuje natomiast technofobia.

Nie jest nawet konieczne oglądanie telewizji, czytanie gazet czy surfowanie po Internecie, aby można było natrafić na „powódź” obrazków. Trudno jest znaleźć dziś przestrzeń społeczną nietkniętą przez wizualizację i komunikację wizualną. Skutkuje to zmianą sposobu myślenia - od słów (zwłaszcza ukazywanych za pomocą znaków graficznych, liter) do obrazów, przedstawiających całe fragmenty rzeczywistości (choć także świata fikcyjnego ${ }^{18}$ ). To obrazy, a nie słowa, stają się podstawowym medium kulturalnej wymiany. Ta właśnie „powódź” obrazów - zdaniem przywołanego wyżej autora - zmienia wszystko: percepcję, myślenie i komunikację. Obrazy bowiem mają znacznie większy oddźwięk niż same słowa, są bardziej emocjonalne i trafiają bezpośrednio. $Z$ drugiej strony zaś ograniczają wyobraźnię i odzwyczajają od myślenia, które potrzebne jest w przypadku recepcji tekstu pisanego. W najdalszych tego konsekwencjach może to prowadzić do powrotu do ery prymitywnej, do myślenia emocjonalnego. Autor podkreśla, że póki co prawo jest tą przestrzenią społeczną, która pozostaje cały czas bardzo sceptyczna w stosunku do ,języka obrazkowego”. Chcąc mieć gwarancję

${ }^{15}$ Zob. E. Schrage, B. Tilleman, A. Verbeke, B. Demarsin, Art and Law, Oxford-Brugge 2008.

${ }^{16}$ Po wpisaniu w wyszukiwarce internetowej hasła „Temida” i ustawieniu polecenia wyszukiwania grafiki, znaleziona została niezliczona liczba najróżniejszych jej przedstawień.

${ }_{17}$ Zob. V. Boehme-Neßler, Pictorial Law: On the Powers of Pictures and Modern Law, London-New York 2011.

${ }^{18}$ Zob. T. Giddens, Comics, law, and aesthetics: Towards the use of graphic fiction in legal studies, „Law and Humanities” 2012, vol. 6, no. 1, s. 85-109. 
lektury tekstu pozbawionego obrazów, możemy sięgnąć właśnie do aktu normatywnego lub do jego komentarza, do którego obrazy niekiedy (w załącznikach) przenikają, ale nadal jest to rzadkość.

Jednak zarówno prawo, jak i prawnicy, nawet wobec świadomej opozycji wobec zarysowanego tu kierunku rozwoju społecznego i konsekwentnego twierdzenia, że prawo opiera się na tekście prawnym, nie mogą ignorować zmieniającej się rzeczywistości. Bowiem jej relewantność wobec prawa jest warunkiem skutecznego działania tego ostatniego. I dlatego można już dziś dostrzec pierwsze oznaki „wizualizacji współczesnego prawa”.

\section{Podsumowanie}

Podsumowując powyższe rozważania - pierwszym etapem dalszych badań winno być uporządkowanie tematyki, którą obejmuje estetyka prawa. W tym ogólnym zarysie spotkać się można nawet z poglądami, że estetyka prawa urasta do rangi autopoetycznego, czyli samoregulującego, samoorganizującego się i samotworzącego się systemu czy idei ${ }^{19}$.

Ważne, aby zdawać sobie sprawę z wykorzystywanych metod badawczych $\mathrm{z}$ jednej strony należy korzystać z całego instrumentarium nauk prawnych, z drugiej zaś konieczne jest sięganie do metod wypracowanych na gruncie estetyki, rozumianej jako ogólnofilozoficzna refleksja nad pięknem (zjawiskiem piękna). Dodatkowo, sięgając do poszczególnych dziedzin twórczości artystycznej, takich jak literatura, teatr, film, sztuki piękne, konieczne jest uwzględnianie dorobku tych dziedzin.

Najważniejsze zaś - często na gruncie prawa i jeszcze częściej na gruncie estetyki, a także, szerzej, innych działów filozofii - jest wartościowanie. Ten, wydawać by się mogło, najbardziej doniosły problem pozostawiam tu jedynie zasygnalizowany.

Natomiast w wymiarze praktycznym najważniejszy, choć nie jedyny wymiar badań z zakresu estetyki prawa, to - w mojej ocenie - zwrócenie się ku problemowi kształtowania świadomości prawnej społeczeństwa za pośrednictwem innych środków niż tekst aktu normatywnego. To zaś pozwala dostrzec, jakże praktycznie doniosłe - choć może póki co bardzo nieprecyzyjne i wysoce intuicyjne może to dać rezultaty. Estetyka prawa dotyczy bowiem istotnego zagadnienia wpływu czynników poznawczo-emocjonalnych na kształt prawa, a także na jego prestiż ${ }^{20}$. Tak więc w zakresie estetyki prawa to właśnie ogląd zewnętrzny - czyli nie tyle samych prawników, ile osób, które za pośrednictwem określonych dzieł kształtują swój obraz sprawiedliwości, prawa i prawników - wysuwać się będzie na pierwszy plan.

\footnotetext{
19 Zob. R. Kevelson (ed.), op. cit., passim.

${ }^{20}$ Por. J. Jabłońska-Bonca, Prawo w kręgu mitów, Gdańsk 1995, s. 15.
} 